Article

\title{
A Pichia anomala Strain (P. anomala M1) Isolated from Traditional Greek Sausage is an Effective Producer of Extracellular Lipolytic Enzyme in Submerged Fermentation
}

\author{
Maria Papagianni ${ }^{1, *}$ and Emmanuel M. Papamichael ${ }^{2}$ \\ 1 Department of Hygiene and Technology of Food of Animal Origin, School of Veterinary Medicine, \\ Aristotle University of Thessaloniki, Thessaloniki 54006, Greece \\ 2 Department of Chemistry, University of Ionnina, Ioannina 45500, Greece; epapamic@cc.uoi.gr \\ * Correspondence: mp2000@vet.auth.gr; Tel.: +30-2310-999804; Fax: +30-2310-999829
}

Received: 4 August 2017; Accepted: 22 August 2017; Published: 30 August 2017

\begin{abstract}
Ayeast isolate, selected for its lipolytic activity from a meat product, was characterized as Pichia anomala. Lipolytic activity, determined on $p$-NPA as esterase, was maximum at $28{ }^{\circ} \mathrm{C}$, $\mathrm{pH} 6.5$, and induced by the short chain triglyceride tributyrin. Fermentations in $2 \mathrm{~L}$ and $10 \mathrm{~L}$ stirred tank bioreactors, with 20 and $60 \mathrm{~g} / \mathrm{L}$ glucose respectively, showed that in the second case lipolytic activity increased 1.74-fold, while the biomass increased 1.57-fold. Under otherwise identical aeration conditions, improved mixing in the $10 \mathrm{~L}$ reactor maintained higher dissolved oxygen levels which, along with the elevated glucose concentration, resulted in significant increase of specific rates of lipolytic activity ( 51 vs. $7 \mathrm{U} / \mathrm{g} / \mathrm{L}$ ), while specific rates of growth and glucose consumption maintained lower. The Crabtree-negative yeast (glucose insensitive growth) exhibited a Pasteur effect at lower dissolved oxygen concentrations while elevated glucose prevented ethanol formation under oxygen saturation. The particular physiological traits can be exploited to obtain significant lipolytic activity in a scalable aerobic process.
\end{abstract}

Keywords: Pichia anomala; characterization; lipolytic activity; esterase; fermentation; metabolism

\section{Introduction}

The yeast Pichia anomala (syn. Wickerhamomyces anomalus, former Hansenula) has been isolated from very diverse habitats, including plants, animals, soil, water, food and hospitals [1,2]. In food and feed, P. anomala has either a beneficial role, as flavor enhancer, biopreservation agent, probiotic, enzyme producer, or a detrimental role, as spoilage yeast. Biopreservation is due to its unusual-for-a-yeast broad spectrum antimicrobial activity against several fungal, yeast, bacterial species and viruses. P. anomala produces several metabolites with potential biotechnological exploitation. Examples, apart from the antimicrobial agents that make it an attractive biocontrol organism for applications in the agri-food sector, include bioethanol, isobutanol, enzymes, sophorolipids, $\gamma$-aminobutyric acid, several volatile organic compounds, and beverage starter cultures [2]. Regarding enzyme production, $P$. anomala strains have been reported as producers of phytase, amylase, $\beta$-glucosidase, peptidase and lipase [3]. P. anomala is therefore a biotechnologically interesting organism which deserves in-depth study in view of future commercialization, as several authors have stressed in their reports [4-6].

A preliminary study with yeast isolates from colonies on the surface of traditional Greek sausages revealed a significant number of Pichia spp. Pichia isolates were tested for lipolytic activity and upon obtaining positive results, further studies were carried out which are reported in the present work. A particular Pichia isolate with the highest lipolytic activity was identified as P. anomala and designated as M1 strain. 
Lipolytic enzyme production is common among yeasts. Only a few yeasts however (mainly Candida, Yarrowia and Geotrichum spp.) are capable of producing lipases and esterases with interesting characteristics and in sufficient amounts that allow characterization as industrial products $[7,8]$. Apart from the established producers, there are several promising lipase-producing yeasts as for example, Issatchenkia orientalis, Kluyveromyces marxianus and others [9]. To the best of our knowledge, $P$. anomala is reported as a lipolytic enzyme producer in only two cases, the works of Banerjee et al. [10] and Ionita et al. [11], both being screening works. Strains of $P$. anomala were cultivated in solid media and shake flask cultures and moderate lipolytic activity, optimum at $\mathrm{pH}$ 6.5-7.5, was detected. In the present work, the P. anomala M1 strain was cultivated in stirred tank bioreactors and produced significant lipolytic activity compared to known sources. The characteristics of lipolytic enzyme production were investigated and evaluated.

Lipolytic enzymes share some important characteristics that can be application specific, e.g., substrate specificity, regionspecificity and chiral selectivity [12]. Novel applications have been successfully established using lipases, as for example in the synthesis of biopolymers, flavor compounds, enantiopure pharmaceuticals, agrochemicals and biosensors [12,13]. Innovations need novel biocatalysts and a useful approach for obtaining them is the isolation of microorganisms from natural sources and subsequent screening for the desired enzymatic activity. P. anomala exhibits many interesting and potentially exploitable characteristics. It can grow under extreme environmental stress conditions with regard to oxygen, $\mathrm{pH}, \mathrm{a}_{\mathrm{w}}$ and sugar concentration $[3,4,14,15]$. As a Crabtree-negative yeast and therefore insensitive to elevated levels of glucose concentrations in its substrate, it can be grown easily in batch fermenters without the need of fed-batch cultivation. These characteristics show an organism of practical significance and therefore a potential industrial microorganism in the case of effective production of a valuable metabolite.

\section{Materials and Methods}

\subsection{Yeast Isolation}

Yeast colonies were transferred from the surface of sausages on agar plates containing YP-glucose medium (YP, yeast-peptone; $1 \%$ yeast extract, $2 \%$ bacteriological peptone, $2 \%$ glucose, $2 \%$ technical agar). The plates were incubated at $28^{\circ} \mathrm{C}$ for 2 days. Selected colonies were sub-cultured on new plates and purified by repeated streaking. The isolated colonies were maintained on YP-glucose agar at $4{ }^{\circ} \mathrm{C}$. The isolated yeast colonies were subjected to standard tests and classification procedures according to Kreger-van Rij [16].

\subsection{Molecular Characterization of an Isolated Pichia Anomala Strain}

Yeast identification was done by amplification and sequence analysis of the ribosomal DNA internal transcribed space region (ITS) $[17,18]$. The following primers were used: ITS1 (5'-CGGGATCCGTAGGTGAACCTGCGG-3') and ITS4 (5'-CGGGATCCTCCGCTTATTGATATGC-3'). The amplification mixture was consisted of: 20 pmol of each primer, 300 ng genomic DNA template, $0.2 \mathrm{mM} \mathrm{dNTP}, 1.5 \mathrm{mM} \mathrm{MgCl}_{2}$, and $1 \mathrm{U}$ Taq polymerase (final volume of $20 \mu \mathrm{L}$ ). Reactions were run for 40 cycles at $94{ }^{\circ} \mathrm{C}$ for $1 \mathrm{~min}$, annealing at $55^{\circ} \mathrm{C}$ for $1 \mathrm{~min}$ and extension at $72{ }^{\circ} \mathrm{C}$ for $2 \mathrm{~min}$, according to Tao et al. [18]. The polymerase chain reaction products were cloned into the plasmid vector pMD18T-Simple (2693 bp) and sequenced. PCR derived sequences were compared with the deposit in the GenBank ITS region (http:/ / www.ncbi.nlm.nih.gov) and the similarity was evaluated using the BLAST program.

\subsection{Yeast Cultivation}

Cultures were grown in $250 \mathrm{~mL}$ Erlenmeyer flasks containing $50 \mathrm{~mL}$ of YP-glucose broth, $\mathrm{pH}$ 6.5, which contained in addition olive oil $(1 \% v / v)$, tributyrin $(1 \mathrm{~g} / \mathrm{L})$, or triolein $(1 \mathrm{~g} / \mathrm{L})$, alternatively. The flasks containing sterile media were inoculated with a loopful of yeast directly from a plated 
culture. The inoculated flasks were incubated in a shaker incubator at $150 \mathrm{rpm}$ and $28{ }^{\circ} \mathrm{C}$ for $48 \mathrm{~h} .20 \mathrm{~h}$ flask cultures were used to inoculate the bioreactors in volumes giving a final optical density at $600 \mathrm{~nm}$ of 0.1 to 0.15 .

Bioreactor cultivations were carried out in two stirred tank bioreactors of different capacities: a 2 L working volume (BioFlo, New Brunswick Scientific, NJ, USA) and a 10 L working volume (BIOFLO 410, New Brunswick Scientific, NJ, USA). The agitator of the 2 L reactor had two six-bladed Rushton-type impellers (52 $\mathrm{mm}$ ). The reactor vessel was equipped with baffles. The agitation system of the $10 \mathrm{~L}$ reactor consisted of three disc turbine impellers, $8 \mathrm{~cm}$ in diameter, with six flat blades. The reactor vessel was also equipped with baffles. The operating stirrer speed in both reactors was $200 \mathrm{rpm}$. The airflow rate was adjusted at $1 \mathrm{~L}$ of air per liter of reactor working volume per minute ( $1 \mathrm{vvm}$ ). The temperature was maintained at $28^{\circ} \mathrm{C}$, while the $\mathrm{pH}$ at 6.5 throughout fermentations by automatic addition of titrants $(1 \mathrm{M} \mathrm{NaOH}$ and $\mathrm{HCl}$ solutions). Dissolved oxygen tension (DOT) was monitored in both reactors during fermentations.

Fermentations in the $2 \mathrm{~L}$ bioreactor carried out using the above-described media and lasted $72 \mathrm{~h}$. In the $10 \mathrm{~L}$ reactor fermentations, the medium was modified to include $60 \mathrm{~g} / \mathrm{L}$ glucose and $1 \mathrm{~g} / \mathrm{L}$ tributyrin and fermentations lasted $96 \mathrm{~h}$. Samples were taken at regular intervals, cells were removed by centrifugation at 14,000 rpm for $10 \mathrm{~min}$, and the supernatants were examined for lipolytic activity. Batch fermentations were repeated at least three times and each sample was analyzed in triplicate.

\subsection{Analytical Methods}

The reagents used throughout the study were analytical grade by Sigma. Growth was estimated by measuring the optical density at $600 \mathrm{~nm}$ and by measuring the cell dry weight (CDW). Broth samples were filtered through pre-weighed glass microfiber filters (Whatman, Maidstone, UK), washed twice and dried in a microwave oven at the defrost setting for $15 \mathrm{~min}$. The filters were placed in a desiccator for the next $24 \mathrm{~h}$ and weighed. The $\mathrm{OD}_{600}$ was correlated with the CDW and 1 unit $\mathrm{OD}_{600}$ equals $0.42 \pm 0.3 \mathrm{mg}$ cells $/ \mathrm{mL}$.

Lipolytic activity was preliminary evaluated on YP-glucose agar plates to which $1 \% v / v$ olive oil had been added. Formation of a clearer halo around yeast colonies after 5 days of incubation at $28^{\circ} \mathrm{C}$ was proof of lipolytic activity. The relative enzyme activity (REA) was calculated by dividing the diameter of the zone of clearance by the diameter of the respective colony (in millimeters). Experiments were carried out in triplicate and mean values are presented.

In liquid culture filtrates, lipolytic activity was assayed using the esters $p$-nitrophenyl palmitate $(p$-NPP) and $p$-nitrophenylacetate ( $p$-NPA) as substrates, following the protocol of our earlier work with molds [19], which was based on the method of Winkler and Stuckmann [20]. The reaction mixture was consisted of $405 \mu \mathrm{L}$ buffer and $45 \mu \mathrm{L}$ of substrate. The buffer was as: $200 \mathrm{mg}$ Triton X-100, $50 \mathrm{mg}$ gum arabic in $50 \mathrm{~mL}$ of $50 \mathrm{mM}$ phosphate buffer, $\mathrm{pH}$ 6.5. As substrate, $15 \mathrm{mg} p$-NPP or $p$-NPA in $10 \mathrm{~mL}$ 2-propanol was used. The reaction mixture was emulsified in an ultrasonic bath for $5 \mathrm{~min}$. $50 \mu \mathrm{L}$ of the sample solution containing the lipolytic enzyme was added to the mixture warmed at $40{ }^{\circ} \mathrm{C}$ and after a $5 \mathrm{~min}$ incubation the reaction was terminated by addition of $0.5 \mathrm{~mL}$ of $2 \%$ Trizma base. Centrifugation was followed at 12,000 rpm/4 min and the OD of the supernatant was measured at $410 \mathrm{~nm}$. One unit (U) of lipase activity was defined as the amount of enzyme that released $1 \mu \mathrm{mol}$ of $p$-nitrophenol $/ \mathrm{min}$ under the specified conditions.

Neutral protease activity was determined in liquid culture filtrates using the casein assay according to Sigma's protocol [21]. Alkaline protease activity was determined using the azocasein assay according to Reichard et al. [22] with the $\mathrm{pH}$ of the $0.1 \mathrm{M}$ Tris-HCl buffer adjusted at 9.0 instead of the suggested 8.0. One unit (U) of protease activity was defined as the absorbance variation in the assay conditions of the above methods.

Glucose concentrations were determined with the glucose oxidase/peroxidase method of Kunst et al. [23]. Ethanol, acetate and glycerol concentrations were determined calorimetrically using assay kits by Sigma-Aldrich (St. Louis, MO, USA) (MAK076, MAK086 and MAK117, respectively). 
All values are given as mean \pm standard deviation in triplicate for each point. Kinetic parameters of growth and production were calculated from raw data using numerical differentiation.

\section{Results and Discussion}

\subsection{Strain Isolation and Identification}

The yeast strain P. anomala M1 studied in this work was isolated from colonies developed on the surface of traditional Greek sausages. Although the yeast population in the sausages is significant, there are no reports in the literature either on its biodiversity or on its role in the development of product characteristics. A preliminary study with yeast isolates from colonies on the surface of the particular type of sausages revealed a significant number of Debaryomyces and Pichia spp. (data not shown). Studies on Spanish and Italian relevant products show the dominance of Debaryomyces and significant numbers of Candida, Pichia, Rhodotorula and Torulopsis spp. [24,25]. The yeasts ferment sugars and have proteolytic and lipolytic activity and therefore, produce a large array of metabolites that contribute to the development of flavor and aroma [26]. In addition, some yeasts metabolize the lactic acid produced by lactic acid bacteria and cause an increase in the $\mathrm{pH}$ toward neutrality which is translated in the product as milder taste [25].

Colonies of the M1 strain on agar plates containing YP-glucose medium were off-white in color, flat, smooth and opaque. Pseudohyphae were not observed, while 1 to 4 ascospores were detected per ascus (Figure 1). The strain was able to grow in media containing as carbon source glucose, sucrose, galactose, and maltose. It was not able to grow on lactose. It could assimilate soluble starch, raffinose, ethanol, glycerol, D-mannitol, as well as lactic and citric acids, but not L-rhamnose. The yeast was able to grow on substrates containing $1.5 \mathrm{M} \mathrm{NaCl}$ (osmotolerant) and in the absence of vitamins, while it produces ethanol under anaerobic conditions (negative Crabtree effect). The yeast was preliminary identified as Pichia while possession of traits such as high osmotolerance, fermentation of sucrose, assimilation of raffinose but not of L-rhamnose, puts it under the species classification of P. anomala according to Kurtzman [1].

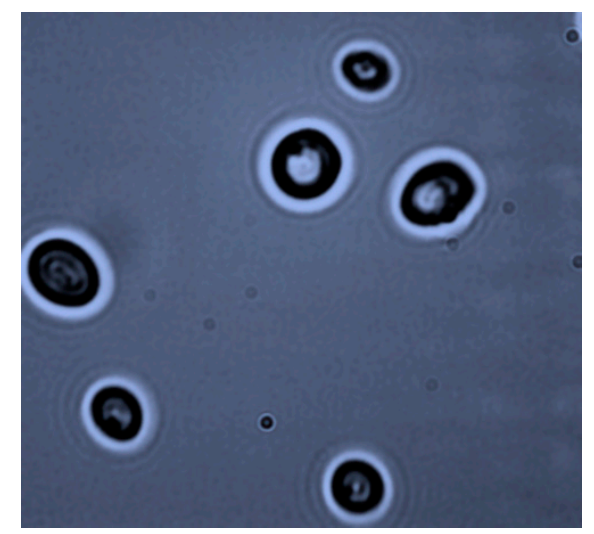

Figure 1. Pichia anomala M1 cell morphology (phase contrast microscopy, $\times 400$ ).

Taxonomic identity of the M1 strain was confirmed through 18s rRNA ITS region cloning and sequencing. Following PCR amplification, a fragment of about $600 \mathrm{bp}$ was obtained (Figure 2). Sequencing results of the ITS region excluding the primers were as: aaggatcattatagtattctattg ccagcgcttaattgcgcggcgataaaccttacacacattgtctagttttttgaactttgctttgggtggtgagcctg gcttactgcccaaaggtctaaacacattttttaatgttaaaacctttaaccaatagtcatgaaaattttaacaaaaattaaaatcttcaaaactttcaacaa cggatctcttggttctcgcaacgatgaagaacgcagcgaaatgcgatacgtattgtgaattgcagattttcgtgaatccgaatctttgaacgcacattg caccctctggtattccagagggtatgcctgtttgagcgtcatttctctctcaaaccttcgggtttggtattgagtgatactctgtcaagggttaacttgaa atattgacttagcaagagtgtactaataagcagtctttctgaaataatgtattaggttcttccaactcgttatatcagctaggcaggttagaagtattttagg ctcggcttaacaacaataaactaaaagtttgacctcacaggtaggactaccegctgaacttaa (570 bp). 


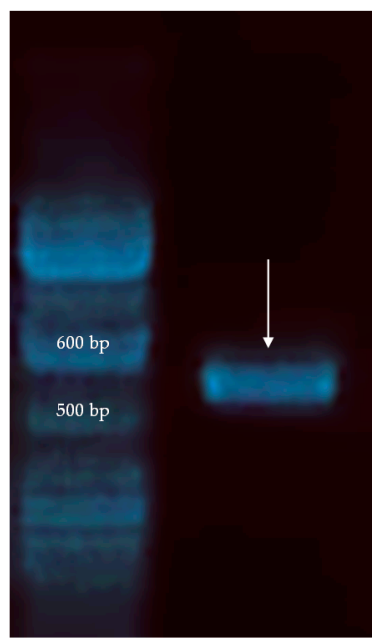

Figure 2. PCR product (pointed) of the internal transcribed spacer (ITS) region of P. anomala M1.

A BLAST search for the above sequence showed that it shared almost complete identity (99\%) with a number of Wickerhamomyces anomalus strains-the name preferred by NCBI for Pichia anomala. The sequence was deposited to GenBank under the accession number BankIt2015357 (MF076893).

\subsection{Relative Lipolytic Activity in Solid State Cultivation}

Research on P. anomala growth conditions has shown that it is able to tolerate a relatively wide range of environmental growth conditions, e.g., temperatures ranging from 3 to $37^{\circ} \mathrm{C}$; $\mathrm{pH}$ values from 2.0 to 12.0; and osmotic conditions as low as $\mathrm{a}_{\mathrm{w}} 0.92$ for $\mathrm{NaCl}$ and 0.85 for glycerol [15]. Tao et al. [18] in their work with $P$. anomala Y1 reported that good growth was obtained in YPD medium with the $\mathrm{pH}$ in the range of 3.5-6.5 and temperature $25-30{ }^{\circ} \mathrm{C}$, while optimum growth conditions were reached at $30^{\circ} \mathrm{C}$ and $\mathrm{pH}$ 5.0. It would be necessary therefore to investigate for lipolytic activity by P. anomala M1 over a wide range of temperatures and $\mathrm{pHs}$ and this was feasible by evaluating first the relative lipolytic activity in solid media containing olive oil, over a temperature range at $\mathrm{pH} 6.5$, since most of yeast and fungal lipases are reported to be most active and stable in neutral and alkaline $\mathrm{pHs}[19,27]$.

Figure 3 shows the relative lipolytic activity of $P$. anomala M1 on YP-glucose agar containing olive oil at various temperatures, ranging from 25 to $40{ }^{\circ} \mathrm{C}$. The $\mathrm{pH}$ of the medium was adjusted at 6.5 . The highest activity was obtained at $28^{\circ} \mathrm{C}$. The lipolytic activity was lower at $30^{\circ} \mathrm{C}$ but significantly higher compared to values obtained at 25 and $35^{\circ} \mathrm{C}$. The relative lipolytic activity at $40{ }^{\circ} \mathrm{C}$ was close to zero. An experiment was also carried out keeping the temperature at $28^{\circ} \mathrm{C}$ and changing the $\mathrm{pH}$ of the medium in a range from 3.0 to 7.5. As it is shown in Figure 4, the highest lipolytic activity was obtained at $\mathrm{pH}$ 6.5. P. anomala $\mathrm{M} 1$ was able to produce lipolytic activity within the $\mathrm{pH}$ range 5.0-7.0 but the relative lipolytic activity values obtained at pHs 6.5 and 6.0 were significantly higher. Lipolytic activity was not detected at pHs 3.0,3.5, and 7.0, while it was marginally detected at pHs 4.0 and 4.5. Considering both Figures 3 and 4, it can be concluded that the optimum conditions of temperature and $\mathrm{pH}$ for lipolytic enzyme production by $\mathrm{P}$. anomala $\mathrm{M} 1$ are $28^{\circ} \mathrm{C}$ and $\mathrm{pH} 6.5$, and these conditions were applied in submerged fermentations. 


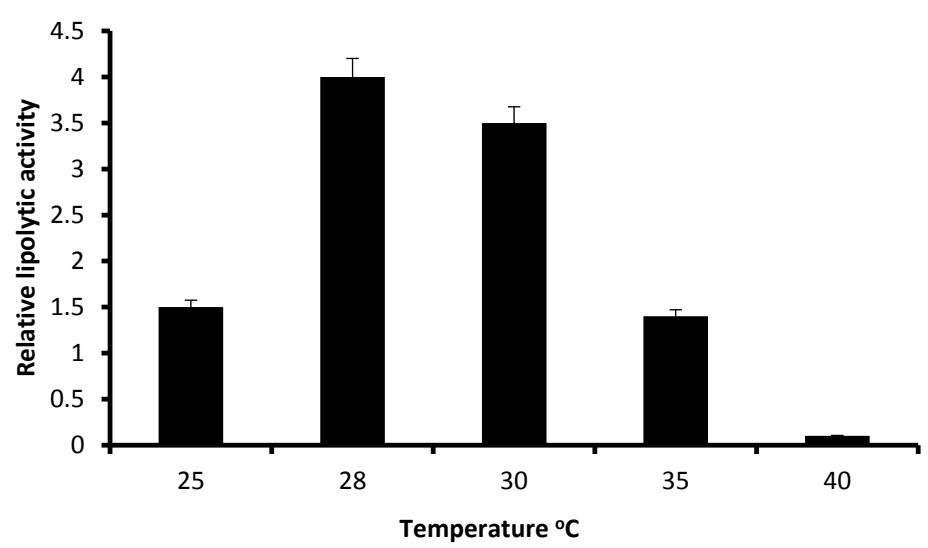

Figure 3. The effect of temperature on the relative lipolytic activity of P. anomala M1 grown on YP-glucose agar supplemented with olive oil at $\mathrm{pH}$ 6.5. Experiments were carried out in triplicate and the Y-error bars represent the standard deviation of the mean value.

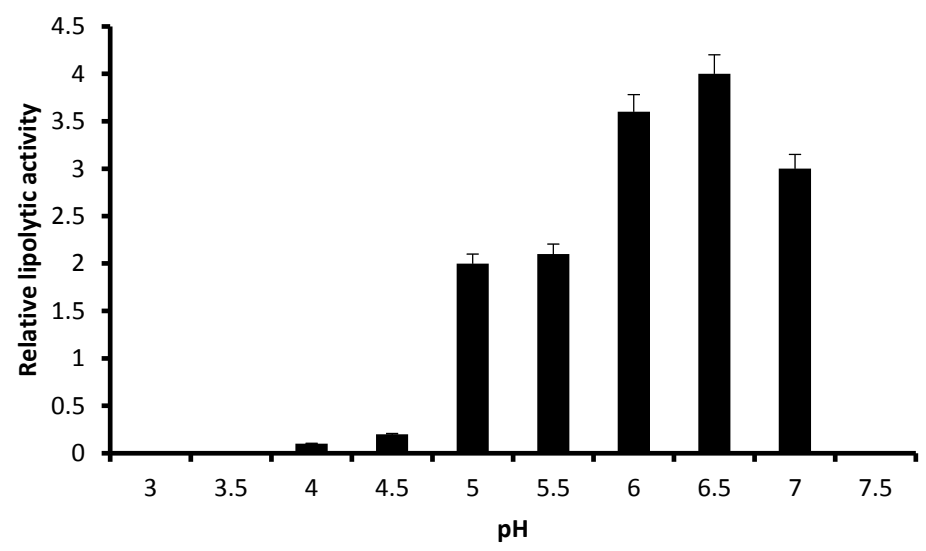

Figure 4. The effect of $\mathrm{pH}$ on the relative lipolytic activity of $P$. anomala $\mathrm{M} 1$ grown on YP-glucose agar supplemented with olive oil at $28{ }^{\circ} \mathrm{C}$. Experiments were carried out in triplicate and the Y-error bars represent the standard deviation of the mean value.

\subsection{Production of Extracellular Lipase in Submerged Fermentation}

Lipases can be distinguished from carboxyl esterases by their substrate spectra, using $p$-NPP (cleaved by lipases) versus $p$-NPA (cleaved by esterases). The lipolytic activity assay produced results only on the $p$-NPA substrate and therefore, the activity is due to an esterase enzyme.

Figures 5 and 6 show the time-courses of biomass and lipolytic activity of P. anomala grown in shaken flasks with olive oil, triburyrin (short chain triglyceride, $\mathrm{C}_{15} \mathrm{H}_{26} \mathrm{O}_{6}$ ) or triolein (long chain triglyceride $\mathrm{C}_{57} \mathrm{H}_{104} \mathrm{O}_{6}$ ) added in the medium as enzyme inducer. There is an obvious enhancement of both growth but mainly lipolytic activity in the case of tributyrin. Comparing results, it appears that final lipolytic activity with tributyrin was 1.91 times higher than the obtained with olive oil while 2.43 times higher than the obtained with triolein. The effect on biomass was not as sound -although results of the same trend were obtained. Biomass yield with tributyrin was 1.16 times higher compared to the obtained with olive oil and 1.47 times higher than that of triolein. In all cases, lipolytic activity increased with increasing biomass and resumed in about $40 \mathrm{~h}$ when cultures were well into the stationary phase of growth. Although in shaken flasks cultivation important process parameters (e.g., the air supply or the culture $\mathrm{pH}$ ) were not under control, the effect of the inclusion of tributyrin in the medium was clear. 


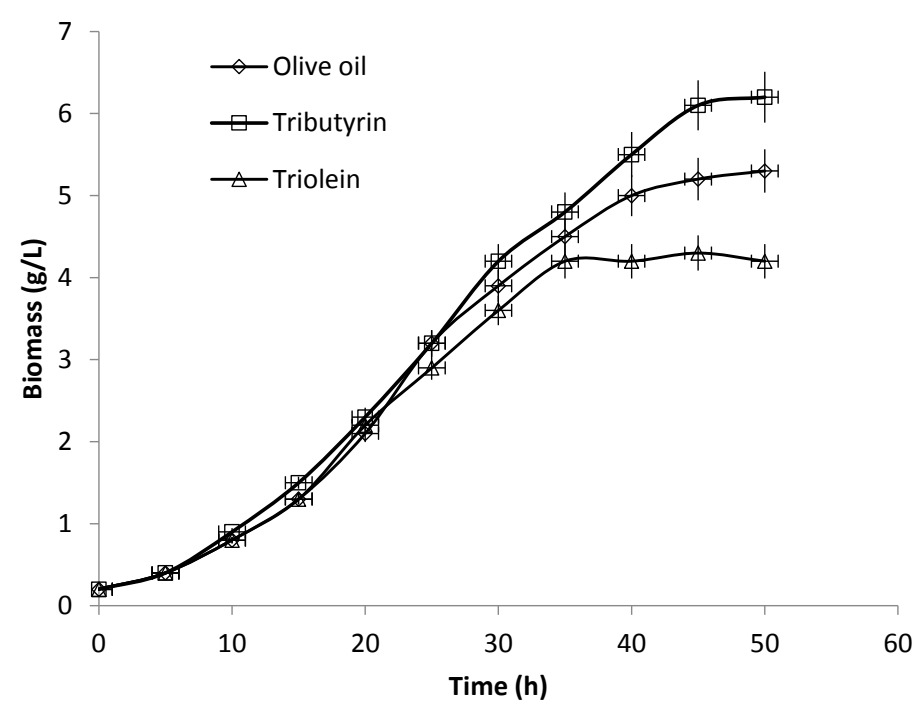

Figure 5. Time courses of biomass concentration of P. anomala M1 in shaken flasks cultures (200 rpm). The YP-glucose medium was supplemented alternatively with olive oil, tributyrin and triolein.

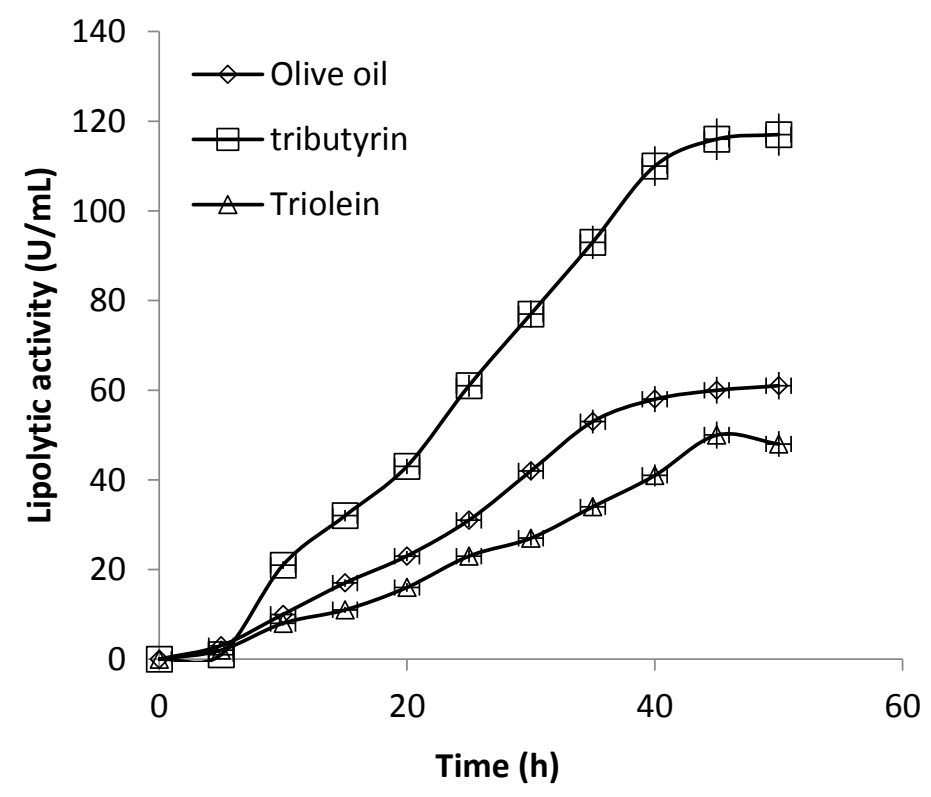

Figure 6. Time courses of extracellular lipolytic activity of P. anomala M1 in shaken flasks cultures (200 rpm). The YP-glucose medium was supplemented alternatively with olive oil, tributyrin and triolein.

The profile of extracellular lipolytic activity of P. anomala M1 was next evaluated in submerged bioreactor cultivations of two different scales under the conditions described in the previous section, using tributyrin as inducer. Concerning oxygen requirements of $P$. anomala, it is known that it is able to grow in both oxygen-replete and oxygen-limited conditions (facultative yeast). However, under aerobic conditions growth rates and biomass yields are significantly higher than those obtained under anaerobic conditions [14]. Since extracellular lipases are products of the primary metabolism with growth-associated characteristics, fermentations were carried out under aerobic conditions to ensure increased growth rates.

Figure 7 shows the time-courses of biomass, lipolytic activity and residual glucose concentrations in a run in the $2 \mathrm{~L}$ stirred tank bioreactor. P. anomala grew exponentially with a maximum specific growth rate $\mu_{\max }$ of $0.17 \mathrm{~h}^{-1}$ and a biomass yield $Y_{\mathrm{x} / \mathrm{s}}$ of $0.43 \mathrm{~g}$ of CDW g of glucose ${ }^{-1}$ (Table 1). 
Only low amounts of ethanol, glycerol and acetate were detected (results at $50 \mathrm{~h}$, Table 1). Dissolved oxygen tension decreased during growth and the lowest levels monitored were $70 \%$ of saturation, which were high enough to consider oxygen limitation (Figure 7). Maximum biomass concentration $(8.6 \mathrm{~g} / \mathrm{L})$ was obtained around $55 \mathrm{~h}$ while maximum lipolytic activity (159 U/L) around $50 \mathrm{~h}$ of fermentation. With depletion of glucose (50 h samples), biomass started decreasing and a sharp fall in lipolytic activity was observed. Running the process for another $24 \mathrm{~h}$ after glucose depletion resulted in a loss of lipolytic activity of the order of $19.2 \%$. This was observed in several cases of lipase production in fermentation [27] and was attributed mainly to proteolytic degradation. Protease activity was determined in the present case and as shown in Figure 7, proteases appeared in the broth after $30 \mathrm{~h}$ of fermentation $(1.2 \mathrm{U} / \mathrm{mL})$ and proteolytic activity was increasing towards the end of the process to reach $11 \mathrm{U} / \mathrm{mL}$. Ethanol, glycerol and acetate were not detected beyond $65 \mathrm{~h}$, indicating their consumption in the absence of glucose.
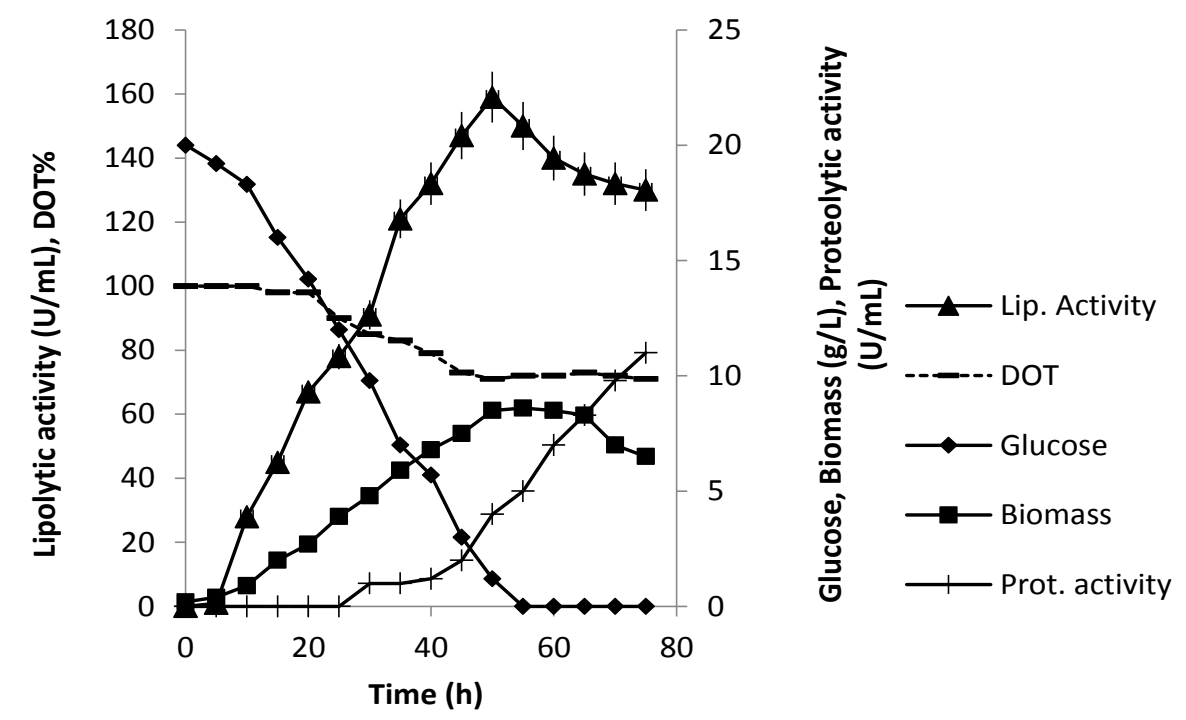

Figure 7. P. anomala fermentation in a $2 \mathrm{~L}$ working volume stirred tank reactor $\left(200 \mathrm{rpm}, 28{ }^{\circ} \mathrm{C}, \mathrm{pH} 6.5\right.$, $1 \mathrm{vvm}$ aeration). The YP-20 g/L glucose medium was supplemented with tributyrin.

Table 1. Kinetic parameters of $P$. anomala M1 cultures. Values are averages \pm standard deviations based on the results of three independent cultivations.

\begin{tabular}{ccc}
\hline Parameter & 2 L Bioreactor 20 g/L Glucose & 10 L Bioreactor 60 g/L Glucose \\
\hline Maximum Specific Growth Rate $\left(\mathbf{h}^{-\mathbf{1}}\right)$ & $0.17 \pm 0.02$ & $0.12 \pm 0.03$ \\
\hline $\begin{array}{c}\text { Maximum Specific Consumption Rate } \\
\text { of Glucose (mmol/g/h) }\end{array}$ & $1.9 \pm 0.2$ & $1.3 \pm 0.3$ \\
\hline Specific Production Rate of & & \\
\hline Lipolytic activity (U/g/h) & $7 \pm 0.8$ & $51 \pm 1.3$ \\
Ethanol (mmol/g/h) & $0.12 \pm 0.02$ & $0.09 \pm 0.03$ \\
Acetate (mmol/g/h) & $0.14 \pm 0.04$ & $0.11 \pm 0.01$ \\
Glycerol (mmol/g/h) & $0.11 \pm 0.03$ & $0.10 \pm 0.02$ \\
\hline Yield on Glucose (g/g) & \\
\hline Biomass & $0.43 \pm 0.14$ & $0.24 \pm 0.02$ \\
Ethanol & $0.03 \pm 0.002$ & $0.05 \pm 0.01$ \\
Acetate & $0.05 \pm 0.01$ & $0.04 \pm 0.02$ \\
Glycerol & $0.02 \pm 0.009$ & $0.02 \pm 0.001$ \\
\hline
\end{tabular}

Figure 7 shows the P. anomala M1 fermentation process in the $10 \mathrm{~L}$ bioreactor with $60 \mathrm{~g} / \mathrm{L}$ initial glucose concentration. Both biomass production and lipolytic activity were higher compared to those obtained in the $2 \mathrm{~L}$ fermentation. The maximum values obtained, were $14.9 \mathrm{~g} / \mathrm{L}$ biomass and $213 \mathrm{U} / \mathrm{mL}$ 
lipolytic activity $(75 \mathrm{~h})$, which is 1.57 times higher biomass, and 1.74 times higher lipolytic activity compared to those obtained from the $2 \mathrm{~L}$ reactor fermentation. Comparing the kinetic parameters for growth in the two reactors it appears that the values for maximum specific growth rateand the yield of biomass on glucose were lower in the $10 \mathrm{~L}$ fermentation: 0.12 compared to $0.17 \mathrm{~h}^{-1}$ and 0.24 compared to $0.43 \mathrm{~g}$ of CDW g of glucose ${ }^{-1} \mathrm{~g}$, respectively (Table 1 ). The lower biomass levels however produced the lipolytic enzyme (in terms of activity) at a higher rate: $0.48 \mathrm{U} / \mathrm{mL} / \mathrm{h}$ compared to $0.06 \mathrm{U} / \mathrm{mL} / \mathrm{h}$ and in terms of specific production rate, $51 \mathrm{U} / \mathrm{g} / \mathrm{h}$ biomass in the $10 \mathrm{~L}$ process compared to $7 \mathrm{U} / \mathrm{g} / \mathrm{h}$ biomass in the $2 \mathrm{~L}$ process (timing: $50 \mathrm{~h}$ ). Glucose concentration fell to zero in $72 \mathrm{~h}$ and the following $24 \mathrm{~h}$ of the process were characterized by declining biomass and enzyme activity levels. The loss of lipolytic activity was $20.1 \%$ in the case of the $10 \mathrm{~L}$ fermentation. Only low amounts of ethanol, glycerol and acetate were detected in this case again (results at $50 \mathrm{~h}$, Table 1). Dissolved oxygen tension decreased during fermentation but higher values were monitored compared to those of the $2 \mathrm{~L}$ bioreactor fermentation: about $85 \%$ of saturation at maximum biomass levels.

Since the lipolytic activity is highly dependent on the experimental conditions and the applied methodology, direct comparisons of the results with those reported for various microbial lipases become rather difficult. However, the obtained values for kinetic parameters and product titers are either comparable or even higher. Kar and co-workers [28] obtained maximum specific rates of extracellular lipase production by $Y$. lipolytica at around $50 \mathrm{~h}$ of fermentation as in the present study, the values however were expressed per million of cells and not per g CDW and cannot be compared since it is a different yeast species. With fungal lipases, the production period is longer as for example with Mucor hiemalis lipase whose maximum activity was obtained at $192 \mathrm{~h}$ of fermentation and reached $110 \mathrm{U} / \mathrm{mL}$ [29], or a Penicillium nalgiovense lipase with a maximum activity of $82 \mathrm{U} / \mathrm{mL}$ at $168 \mathrm{~h}$ of fermentation [19].

The applied culture conditions in the $10 \mathrm{~L}$ bioreactor (Figure 8) resulted in a significant increase in the specific rate of lipolytic activity while the specific rates of growth and glucose consumption were decreased compared to those of the $2 \mathrm{~L}$ bioreactor. The main differences between the two systems were the concentrations of glucose and the dissolved oxygen tension. P. anomala is a respiratory yeast that lacks a Crabtree effect and therefore, there is no induction of alcoholic fermentation by high glucose concentrations. In addition, similarly to the other respiratory yeast $K$. lactis, P. anomala exhibits minor fermentation despite the elevated activities of the key fermentative enzymes PDC and ADH [14,30]. This metabolic profile was apparent in the present study. Although the same stirrer speed (200 rpm) and air supply rate $(1 \mathrm{vvm})$ were applied in the two reactor systems, the dissolved oxygen tension was maintained at higher levels in the $10 \mathrm{~L}$ bioreactor despite the increased biomass concentration. This can be explained by a more efficient mixing regime in the $10 \mathrm{~L}$ reactor that facilitated a smaller mixing time of the broth, however, mixing studies were not undertaken at that stage to quantify the effects. The decrease in DOT in the $2 \mathrm{~L}$ bioreactor may have acted as the inducing stimulus for the activation of fermentative metabolism and the increased glucose consumption rate points to an ongoing Pasteur effect. Glucose availability however, did not induce ethanol formation.

Intensive studies of $P$. anomala metabolism and physiology in response to oxygen and glucose availability carried out by Fredlund and co-workers (2004) [14] showed that with the particular yeast, the signals that induce respiratory and fermentative metabolism are completely different from those known for Saccharomyces cerevisiae. Respiratory growth was obtained from aerobic batch cultures with a high glucose concentration and fermentation could be induced by shifting the cultures to oxygen limitation (shift from $50 \%$ to $0 \%$ DOT). Oxygen therefore is the main regulator of the central energy metabolism while glucose does not repress respiration but possibly repress the ethanol assimilation pathway. Having this metabolic and physiological background, lipolytic enzyme production by P. anomala appears to be advantageous compared to other sources as it can take place under oxygen-saturated conditions using substrates with elevated glucose concentrations. 


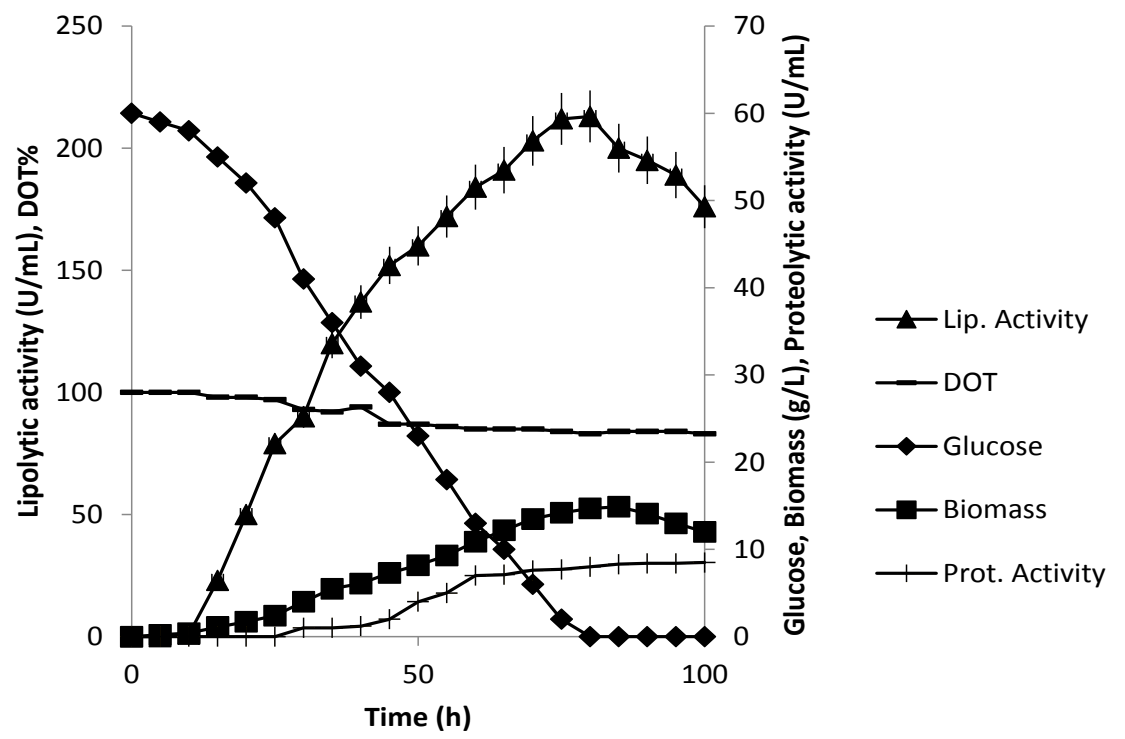

Figure 8. P. anomala fermentation in a $10 \mathrm{~L}$ working volume stirred tank reactor $\left(200 \mathrm{rpm}, 28^{\circ} \mathrm{C}, \mathrm{pH} 6.5\right.$, $1 \mathrm{vvm}$ aeration). The YP-60 g/L glucose medium was supplemented with tributyrin.

From the applications point of view, the non-conventional yeast $P$. anomala has been extensively studied mainly as a biopreservation agent for various post-harvest systems. Although it was reported in the past as lipase-positive yeast, its production potential in fermentation systems was not evaluated. The current study shows that a wild strain isolated from a rich in fat meat product can produce significant lipolytic activity in a scalable aerobic process. Further studies will focus on the characteristics and properties of the produced esterase as well as in the process itself. Factors for example, identified in this study as controlling process parameters, e.g., the DOT, should be studied in a scaling-up perspective.

\section{Conclusions}

This study shows that a wild strain of P. anomala is capable of producing extracellular lipolytic (esterase) activity in a process with practical significance. Experiments carried out in agar plates, shaken flasks, a $2 \mathrm{~L}$ stirred tank bioreactor and a $10 \mathrm{~L}$ stirred tank bioreactor showed that by setting the appropriate conditions the physiological traits of the particular yeast can be exploited for effective enzyme production. The Crabtree-negative yeast $P$. anomala exhibits a Pasteur effect at lower dissolved oxygen concentrations but elevated glucose concentrations are not inhibitory and depress ethanol formation in an oxygen-saturated substrate. The main stimulus for the regulation of central carbon metabolism as it appears from its effects on the specific rates of growth and enzyme production is oxygen and, therefore, setting an aerobic process with a high glucose concentration in the substrate advances enzyme production.

Author Contributions: Both authors contributed equally in this study.

Conflicts of Interest: The authors declare no conflict of interest.

\section{References}

1. Kurtzman, C.P.; Fell, J.W. (Eds.) The Yeasts, a Taxonomic Study; Elsevier: Amsterdam, The Netherlands, 1998.

2. Passoth, V.; Fredlund, E.; Druvefors, U.Ä.; Schnürer, J. Biotechnology, physiology and genetics of the yeast Pichia anomala. FEMS Yeast Res. 2006, 6, 3-13. [CrossRef] [PubMed]

3. Walker, G.M. Pichia anomala: Cell physiology and biotechnology relative to other yeasts. Antonie van Leeuwenhoek 2011, 99, 25-34. [CrossRef] [PubMed] 
4. Fletcher, E.; Feizi, A.; Kim, S.; Siewers, V.; Nielsen, J. RNA-Seq analysis of Pichia anomala reveals important mechanisms required for survival at low pH. Microb. Cell Fact. 2015, 14, 143. [CrossRef] [PubMed]

5. Passoth, V.; Olstorpe, M.; Schnürer, J. Past, present and future research directions with Pichia anomala. Antonie Van Leeuwenhoek 2011, 99, 121-125. [CrossRef] [PubMed]

6. Schneider, J.; Rupp, O.; Trost, E.; Jaenicke, S.; Passoth, V.; Goesmann, A.; Tauch, A.; Brinkrolf, K. Genome sequence of Wickerhamomyces anomalus DSM 6766 reveals genetic basis of biotechnologically important antimicrobial activities. FEMS Yeast Res. 2012, 12, 382-386. [CrossRef] [PubMed]

7. Goncalves, F.A.G.; Colen, G.; Takahasi, J.A. Yarrowia lipolytica and its multiple applications in the biotechnological industry. Sci. World J. 2014. [CrossRef]

8. Satyanarayana, T.; Kunze, G. Yeast Biotechnology: Diversity and Applications; Springer: Berlin, Germany, 2009.

9. Stergiou, P.Y.; Foukis, A.; Sklivaniti, H.; Zacharaki, P.; Papagianni, M.; Papamichael, E.M. Experimental investigation and optimization of process variables affecting the production of extracellular lipase by Kluyveromyces marxianus IFO 0288. Appl. Biochem. Biotechnol. 2012, 168, 672-680. [CrossRef] [PubMed]

10. Banerjee, S.; Sengupta, I.; Majumdar, S.K. Lipase Production by Hansenula anomala var.Schnegii. J. Food Sci. Technol. 1985, 22, 137-139.

11. Ionita, A.; Moscovici, M.; Popa, C.; Vamanu, A.; Popa, O.; Dinu, L. Screening of yeast and fungal strains for lipolytic potential and determination of some biochemical properties of microbial lipases. J. Mol. Catal. B. Enzym. 1997, 3, 147-151. [CrossRef]

12. De Miranda, A.S.; Miranda, L.S.M.; de Suza, R.O.M.A. Lipases: Valuable catalysts for dynamic kinetic resolutions. Biotechnol. Adv. 2015, 33, 372-393. [CrossRef] [PubMed]

13. Faber, K. Biotransformations in Organic Chemistry, 6th ed.; Springer: Berlin, Germany, 2011.

14. Fredlund, E.; Blank, L.M.; Schnürer, J.; Sauer, U.; Passoth, V. Oxygen- and glucose-dependent regulation of central carbon metabolism in Pichia anomala. Appl. Environ. Microbiol. 2004, 70, 5905-5911. [CrossRef] [PubMed]

15. Fredlund, E.; Druvefors, U.; Ligsten, K.J.; Boysen, M.E.; Schnürer, J. Physiological characteristics of the biocontrol yeast Pichia anomala J121. FEMS Yeast Res. 2002, 2, 395-402. [PubMed]

16. Kreger-van Rij, N.J.W. The Yeasts: A Taxonomic Study, 3rd ed.; Elsevier: Amsterdam, The Netherlands, 1984.

17. Caggia, C.; Restuccia, C.; Pulvirenti, A.; Giudici, P. Identification of Pichia anomala isolated from yoghurt by RFLP of the ITS region. Int. J. Food Microbiol. 2001, 71, 71-73. [CrossRef]

18. Tao, N.; Gao, Y.; Liu, X. Isolation and characterization of a Pichia anomala strain: A promising candidate for bioethanol production. Braz. J. Microbiol. 2011, 42, 668-675. [CrossRef] [PubMed]

19. Papagianni, M. An evaluation of the proteolytic and lipolytic potential of Penicillium spp. isolated from traditional Greek sausages in submerged fermentation. Appl. Biochem. Biotechnol. 2014, 172, 767-775. [CrossRef] [PubMed]

20. Winkler, U.K.; Stuckmann, M. Glycogen, hyaluronate, and some other polysaccharides greatly enhance the formation of exolipase by Serratia marcescens. J. Bacteriol. 1979, 138, 663-670. [PubMed]

21. Sigma-Aldrich. Universal Protease Activity Assay: Casein as a Substrate. 2013. Available online: http:/ / www.sigmaaldrich.com/life-science/learning-center/life-science-video/universal-protease.html. (accessed on 1 July 2017).

22. Reichard, U.; Buttner, S.; Eifferst, H.; Staib, F.; Ruchel, R. Purification and characterisation of an extracellular serine proteinase from Aspergillus fumigatus and its detection in tissue. J. Med. Microbiol. 1990, 33, 243-251. [CrossRef] [PubMed]

23. Kunst, A.; Draeger, B.; Ziegenhom, J. Colorimetric methods with glucose oxidase. Methods Enzym. Anal. 1986, 6, 178-185.

24. Gardini, F.; Suzzi, G.; Lombardi, A.; Galgano, F.; Crudele, M.A.; Andrighetto, C.; Schirone, M.; Totalo, R. A survey of yeast in traditional sausages of southern Italy. FEMS Yeast Res. 2001, 1, 161-167. [CrossRef] [PubMed]

25. Mendoça, R.C.S.; Gouvêa, D.M.; Hungaro, H.M.; Sodré, A.F.; Querol-Simon, A. Dynamics of the yeast flora in artisanal country style and industrial dry cured sausage (yeast in fermented sausage). Food Control 2013, 29, 143-148. [CrossRef]

26. Durá, M.A.; Flores, M.; Toldrá, F. Effect of growth phase and dry-cured sausage processing conditions on Debaryomyces spp. generation of volatile compounds from branched-chain amino acids. Food Chem. 2004, 86, 391-399. [CrossRef] 
27. Bussamara, R.; Fuentefria, A.M.; de Oliveira, E.S.; Broetto, L.; Simcikowa, M.; Valente, P.; Schrank, A.; Vainstein Henning, M. Isolation of a lipase-secreting yeast for enzyme production in a pilot-plant scale batch fermentation. Biores. Technol. 2010, 101, 268-275. [CrossRef] [PubMed]

28. Kar, T.; Delvigne, F.; Masson, M.; Destain, J.; Thonart, P. Investigation of the effect of different extracellular factors on the lipase production by Yarrowia lipolytica on the basis of a scale-down approach. J. Ind. Microbiol. Biotechnol. 2008, 35, 1053-1059. [CrossRef] [PubMed]

29. Hiol, A.; Jonzo, M.D.; Bruet, D.; Comeu, L. Production, purification and characterization of an extracellular lipase from Mucor hiemalis f. hiemalis. Enzyme Microb. Technol. 1999, 25, 80-87. [CrossRef]

30. Kiers, J.; Zeeman, A.M.; Luttic, C.; Thiele, C.; Castrillo, J.I.; Steensma, H.Y.; van Dijken, J.P.; Pronk, J.T. Regulation of alcoholic fermentation in batch and chemostat cultures of Kluyveromyces lactis CBS 2359. Yeast 1998, 14, 459-469. [CrossRef]

(C) 2017 by the authors. Licensee MDPI, Basel, Switzerland. This article is an open access article distributed under the terms and conditions of the Creative Commons Attribution (CC BY) license (http://creativecommons.org/licenses/by/4.0/). 